\title{
Determining the Optimum Tilt Angles to Maximize the Incident Solar Radiation - Case of Study Pristina
}

\author{
Xhevat Berisha ${ }^{a^{*}}$, Arianit Zeqiria and Drilon Meha ${ }^{a}$ \\ Department of Thermoenergetics and Renewable Energy, Faculty of Mechanical Engineering, Pristina, Str. Sunny Hill n.n. 10000 \\ Kosovo
}

\begin{abstract}
Solar energy is derived from photons of light coming from the sun in a form called radiation. Solar energy finds extensive application in air and water heating, solar cooking, as well as electrical power generation, depending on the way of capturing, converting and distribution. To enable such application, it is necessary to analyze the horizontal tilt angle of horizontal surfaces - in order that when the solar energy reaches the earth surface to be completely absorbed. This paper tends to describe the availability of solar radiation for south-facing flat surfaces. The optimal monthly, seasonal, and annual tilt angles have been estimated for Pristina. The solar radiation received by the incident plane is estimated based on isotropic sky analysis models, namely Liu and Jordan model. The annual optimum tilt angle for Pristina was found to be $34.7^{\circ}$. The determination of annual solar energy gains is done by applying the optimal monthly, seasonal and annual tilt angles for an inclined surface compared to a horizontal surface. Monthly, seasonal and annual percentages of solar energy gains have been estimated to be $21.35 \%$, $19.98 \%$, and $14.43 \%$. Losses of solar energy were estimated by $1.13 \%$ when a surface was fixed at a seasonal optimum tilt angle, and when it was fixed at an annual optimum tilt angle, those losses were $5.7 \%$.
\end{abstract}

Keywords: solar energy; gains; estimation; tilt angle; South-facing.

Article History: Received February 15 ${ }^{\text {th }}$ 2018; Received in revised form May 12 ${ }^{\text {th }}$ 2018; Accepted June $2^{\text {nd }} 2018$; Available online

How to Cite This Article: Berisha, Xh., Zeqiri, A. and Meha, D. (2018) Determining the Optimum Tilt Angles to Maximize the Incident Solar Radiation - Case of Study Pristina. Int. Journal of Renewable Energy Development, 7(2), 123-130.

https://doi.org/10.14710/ijred.7.2.123-130

\section{Introduction}

Because of a significant increase in energy demands, conventional energy sources are being violently consumed, leading to an increase of pollutants released from the burning of fossil fuels. Knowing that solar equipment's do not have moving parts, they are considered to have a greater lifetime and do not cause pollution compared to other energy sources. Therefore, solar energy is considered amongst the most common solutions production thermal energy, for heat water and district heating, and electricity energy.

Because of a significant increase in energy demands, conventional energy sources are being violently consumed, leading to an increase of pollutants, which are released from the burning of fossil fuels. Knowing that solar equipment's do not have moving parts, they are considered to have a greater lifetime and do not cause pollution compared to other energy sources. Therefore, solar energy is considered as one of the best solutions.

In most cities of Kosovo, the maximum global solar radiation is reached during July, whereas the minimum during December.

The performance of solar equipment's (i.e. solar collectors for water and air heating, power generation, photovoltaic systems, etc.), is closely related to the inclined angle from the surface that absorbs the light of the sunshine (i.e. with their placement plane).

Sun tracking systems are used to increase the acceptance of solar radiation. The usage of these systems has a significant cost to the normal operation of an entire system, due to the consumption of a considerable energy generated.

Hence, the estimation of the optimal tilt angle has a crucial effect on the solar technology. Additionally, as stated by Eldin et al. (2016), trackers need periodic maintenance and calibration and require input energy for their operation which is in the range of $5-10 \%$ of the energy produced. Further, as explained by Sinha and Chandel (2016), trackers are made up of sophisticated mechanical parts which add to capital cost and an increase in cost of absolute power produced from solar PV panels. Other method suggested by Yakup et al. (2001) is to optimize the orientation of flat surfaces at optimum tilt inclination $\left(\beta_{\text {opt }}\right)$. Vieira et al. (2016) performed an experimental study which suggested that the sun tracking panel exhibited a low average gain in power generated, relative to the fixed panel. In another study conducted by Sinha and Chandel (2016), it was reported that the horizontal axis weekly adjustment tracking systems and vertical axis continuous adjustment

\footnotetext{
* Corresponding author: xhevat.berisha@uni-pr.edu
} 
tracking systems, produced less energy annually than the existing PV systems at fixed tilt. As suggested by Ahmad and Tiwari (2009), optimum tilt inclination can be adjusted daily, monthly, seasonally, bi-annually or annually for maximizing the performance of the device in use. In the city of Shterpca, the annual solar radiation is estimated to be $1333.7 \mathrm{kWh} / \mathrm{m}^{2} /$ year, while in the city of Gjakova $1495.1 \mathrm{kWh} / \mathrm{m}^{2} /$ year. Furthermore, as suggested by Naumann and Pireci (2012), knowing the geographical position of the aforementioned cities, we can accept an average value of solar radiation of $1400 \mathrm{kWh} / \mathrm{m}^{2} /$ year for the climate conditions of Kosovo.

This solar radiation potential can be utilized in desalination, solar-thermal collectors, building heating, day-lighting, and Photovoltaic (PV) Cells etc. Researchers are therefore concerned to maximize the amount of useful energy that can be extracted through the incoming solar radiations. Yakup and Malik (2001) implied that it is believed that proper installation of these devices can make a remarkable change in the observed performance. Hence, climatology, latitude, orientation, tilt angle, azimuth angles and the usage over a period in a specific geographical region affect the performance of the abovementioned devices.

The tilt of a surface $(\beta)$ is one of the significant factors that considerably affect the availability of solar radiation on a flat surface. As suggested by Ahmad et al. (2016) and Okoye et al. (2016) optimization of the performance of solar-based devices requires option-like solar tracking equipment, which follow trajectories of Sun's motion to enhance incident radiation. However, these options are not always economical.

The Optimization of the tilt angle has been conducted by numerous researchers including Bakirci (2012); Ertekin et al. (2008); Stanciu et al. (2016); Hartner (2015); Calabr (2013) and Mehleri (2010) for different countries in Europe, Soulayman and Sabbagh (2015); Jafari et al. (2012); Jafarkazemi (2012); Moghadam et al. (2011); Jafarkazemi (2013); Tamimi and Sowayan (2012); Benghanem (2011); Elminir et al. (2006); Alatarawneh et al. (2016); Shariah et al. (2002) and Skeiker (2009) for Middle East and lastly Khahro et al. (2015); Krishna et al. (2015); Handoyo et al. (2013); Li and Lam (2007); Tang and Wu (2004); Eke (2011) and Siraki and Pillay (2012) for Asia.

\section{Location of study}

Pristina - the capital city $-\left(42.65^{\circ} \mathrm{N}, 21.15^{\circ} \mathrm{E}\right.$ and $573 \mathrm{~m}$ a.s.l.) is situated in the north-east of Kosovo characterized by a humid continental climate with maritime influences. Summers are warm and winters are relatively cold and snowy.

According to a study conducted by by Naumann and Pireci (2012) for zones with solar radiation potential, Kosovo has been divided into four zones of rough solar radiation.

Population density in Kosovo is greater in the central and western parts compared to the eastern parts. The highest values of solar radiation are shown in Zone 1 while the lowest appear in Zone 4. The division of municipalities by area of solar radiation intensity is presented in Table 1 provided by Naumann and Pireci (2012).
Table 1

Division of Kosovo municipalities according to climate sub-zones

\begin{tabular}{cllll}
\hline Nr & Zone 1 & Zone 2 & Zone 3 & Zone 4 \\
\hline 1 & Peje & Prizren & Podujeve & Gjilan \\
2 & Decan & Dragash & Kamenice & Viti \\
3 & Gjakove & Mitrovice & Istog & Kacanik \\
4 & Kline & Skenderaj & Zubin Potok & Shterpce \\
5 & Rahovec & Lipjan & Leposavic & \\
6 & Suhareke & Pristine & Zvecan & \\
7 & Malisheve & Ferizaj & Vushtrri & \\
\hline
\end{tabular}

Source: Naumann and Pireci (2012).

\section{Methodology of analysis concepts - Data on solar radiation}

For the purposes of this paper, we used meteorological data for daily mean global radiation and diffuse radiation on a horizontal plane, extracted from the information provided by the Meteorological Institute of Kosovo and are presented in Fig. 1.

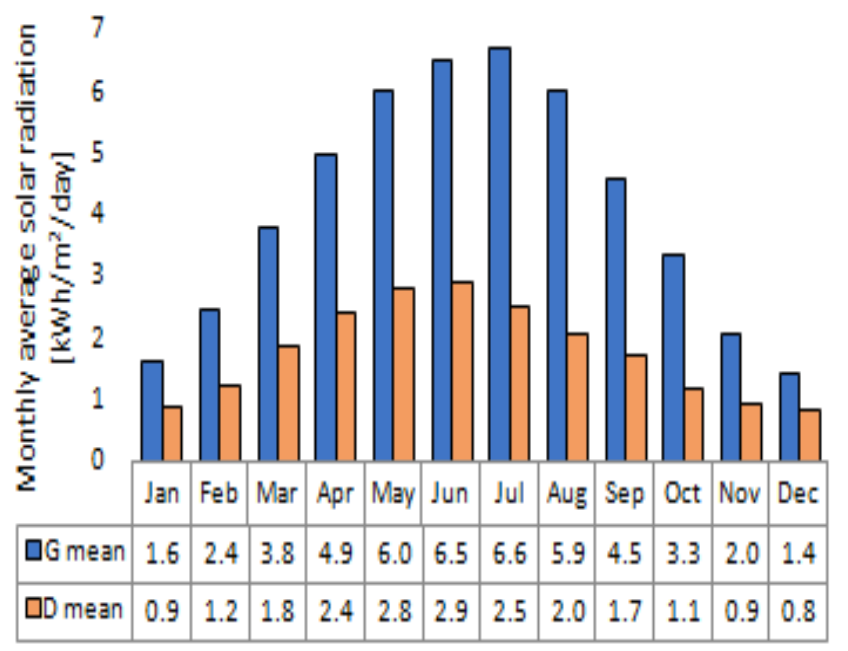

Fig. 1 Monthly means daily global radiation $G_{m}$ and diffuse radiation $\mathrm{D}_{\mathrm{m}}$ on horizontal plane of Pristina

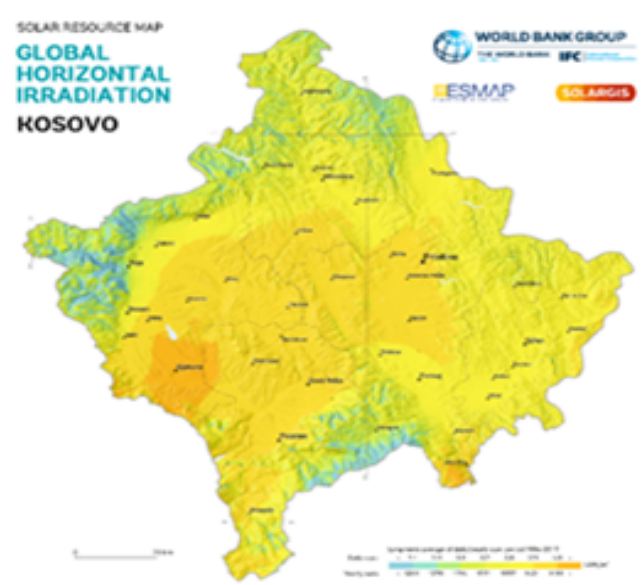

Fig. 2 Global horizontal radiation in Kosovo Source: $h t t p: / / g l o b a l s o l a r a t l a s . i n f o / d o w n l o a d s /$ kosovo 


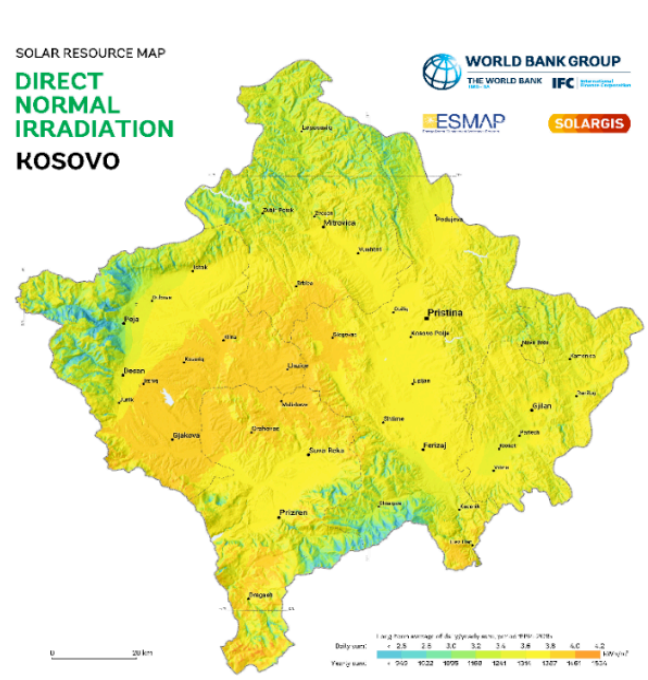

Fig. 3 Direct normal radiation in Kosovo Source: http://globalsolaratlas.info/downloads / kosovo

In Fig. 2 presents the yearly average of global radiation, horizontal plane, in Kosovo. As per Fig. 1, the highest value of average global solar radiation in Kosovo is in the city of Gjakova. In Fig. 3 is presented the annual average direct normal radiation, horizontal plane, for Kosovo cities.

\section{Estimation of solar radiation on the inclined surface}

Global solar radiation monthly mean data for an inclined surface are necessary for the designing of solar energy systems. These data are often not available. Therefore, we need tend to estimate the data by considering the monthly average of the global solar radiation on the horizontal plane (presented in Fig. 3.), which is the most important parameter for estimating the optimum tilt angle.

The study presents a simple and universal method of determining the mean monthly global radiation based on the existing methodology given by Paul et al. (2016).

As defined by Liu and Jordan (1962), Jakhrani et al. (2013), and Muneer (2004), the total solar energy received on an inclined surface is "the sum of the beam, diffuse, and reflected radiation".

Thus, the total solar radiation monthly average (in $\mathrm{kWh} / \mathrm{m}^{2} /$ day) for an inclined surface is calculated as follows:

$$
\bar{H}_{T}=\bar{H}_{B}+\bar{H}_{D}+\bar{H}_{R}
$$

Mathematically, the optimal value of the tilt angle $\left(\beta_{o p t}\right)$ is determined by differencing Eq. 1 depending on the angle of inclination $(\beta)$.

$$
\begin{gathered}
\frac{d}{d \beta}\left(\bar{H}_{T}\right)=0 \\
\bar{H}_{T}=\bar{R} \cdot \bar{H}
\end{gathered}
$$

$\bar{R}$ presents the ratio between the global radiation monthly mean on an inclined surface than for the horizontal one. Below is presented the $\bar{R}$ ratio as defined by Liu and Jordan (1962) and Bakirci (2012):

$$
\bar{R}=\left(1-\frac{\bar{H}_{D}}{\bar{H}}\right) \bar{R}_{b}+\frac{\bar{H}_{D}}{\bar{H}}\left(\frac{1+\cos \beta}{2}\right)+\rho\left(\frac{1-\cos \beta}{2}\right)
$$

$\bar{H}$ and $\overline{H_{d}}$ are are the monthly average daily global and diffuse radiations on a horizontal surface; $\overline{R_{b}}$ is the ratio of the mean daily direct radiation on an inclined surface to that on a horizontal surface, and the parameters correlated by ground reflection coefficient (albedo $\rho=0.2$ ); $\beta$ represents the tilt angle. Radiation beam falling on an inclined surface is given by Liu and Jordan (1962):

$$
\bar{H}_{B}=\left(\bar{H}-\bar{H}_{d}\right) \cdot \bar{R}_{b}
$$

As defined by Jakhrani et al. (2013), the reflected radiation is "the part of the total solar radiation that is reflected by the surface of the earth, and by any other surface intercepting object such as trees, terrain or buildings on to a surface exposed to the sky is termed as ground reflected radiation". Reflected radiation on an inclined surface is given by:

$$
\bar{H}_{R}=\bar{H} \cdot \bar{R}_{r}
$$

$\overline{R_{r}}$ is the reflected conversion factor:

$$
\bar{R}_{r}=\rho\left(\frac{1-\cos \beta}{2}\right)
$$

Where $\rho$ is the constant that depends on the type of ground surrounding tilted surfaces and is called the ground reflectance or albedo. According to Kondratev (1969), the value of albedo most commonly used is $\rho=0.2$ for hot and humid tropical locations, $\rho=0.5$ for dry tropical locations, and $\rho=0.9$ for snow covered ground. The ground reflection coefficient is assumed $\rho=0.2$ for the climate conditions in Pristina.

Widen (2009) defines the diffused radiation $\left(\bar{H}_{D}\right)$ as the fraction of total solar radiation, received from the sun when its direction has been changed by atmospheric scattering. The diffused radiation direction o is highly variable and difficult to determine. It is a function of the condition of cloudiness and atmospheric clearness which is extremely unpredictable. Diffused radiation fraction is the sum of isotropic, circumsolar, and horizon brightening components. The isotropic diffuse radiation component is "received evenly from the entire sky dome" as defined by Robinson and Stone (2004). The circumsolar diffuse part is received from the onward solar radiation dispersion and focused around the sun sky section. The horizon brightening component is concentrated near the horizon and it is most visible during clear skies as presented by Liu and Jordan (1960). In general, isotropic, circumsolar, and horizon brightening factors compose the diffuse fraction of radiation on an inclined surface. In Liu and Jordan (1960) model, the diffuse radiation was assumed isotropic only while circumsolar and horizon brightening were taken as zero.

Diffuse radiation falling on an inclined surface is calculated as follows:

$$
\bar{H}_{D}=\bar{H}_{d} \cdot \bar{R}_{d}
$$

Where $\overline{R_{d}}$ is the diffuse conversion factor presenting the ratio of diffuse solar radiation on an inclined surface to diffuse solar radiation on a horizontal surface, given as: 


$$
\bar{R}_{d}=\left(\frac{1+\cos \beta}{2}\right)
$$

The monthly average data of the daily global radiation, taken from Fig. 3., are used in the following expressions for determination of other parameters. According to Paul et al. (2016), the following expression determines the monthly average of daily diffuse radiation:

$$
\begin{aligned}
& \frac{\overline{\bar{H}_{d}}}{\bar{H}}=0.96268-\left(1.45200 \cdot K_{T}\right)+\left(0.27365 \cdot K_{T}^{2}\right) \\
& +\left(0.04279 \cdot K_{T}^{3}\right)+(0.000246 \cdot(S S H A)) \\
& +(0.001189 \cdot(N H S A))
\end{aligned}
$$

Where SSHA is the sunset hour angle in degrees on the "monthly average day (n)", which can be calculated from the following equation:

$$
\text { SSHA }=\omega_{s}^{\prime}=\cos ^{-1}(-\tan (\phi-\delta) \tan \delta)
$$

NHSA is the noon solar angle from the horizon in degrees on the "monthly average day ( $n)$ " and can be estimated as follows:

$$
N H S A=90-|\phi-\delta|
$$

The monthly average clearness index $\bar{K}_{T}$ is the ratio of monthly average daily radiation on a horizontal surface to the monthly average daily extraterrestrial radiation and can be obtained from:

$$
\bar{K}_{T}=\bar{H} / \bar{H}_{0}
$$

Where, $\overline{H_{0}}$ is the monthly mean daily extraterrestrial radiation on a horizontal surface, and it is calculated using Albotenau et al. (2015) formula:

$$
\begin{aligned}
& \bar{H}_{0}=\frac{24 \times 3600}{\pi} I_{0}\left(1+0.033 \cos \left(\frac{360 n}{365}\right)\right) \\
& \left(\cos \phi \cos \delta \sin \omega_{s}+\frac{2 \pi \omega_{s}}{360} \sin \phi \sin \delta\right)
\end{aligned}
$$

Where $I_{0}$ represents the solar constant $\left(1367 \mathrm{~W} / \mathrm{m}^{2}\right) ; n$ shows the number of daily readings in a given month, counted from 1 January (1-365); $\phi$ is location geographic latitude; $\omega_{s}$ is sunrise/sunset angle on a horizontal surface; $\delta$ is sun declination. As defined by Cooper (1969), the "monthly average day" is the day of the month, whose solar declination is closest to the average declination for that month. The maximum value of the declination angle $(\delta)$ is $+23.45^{\circ}$ during June $21^{\text {st }}-22^{\text {nd }}$, while its minimum value is $-23.45^{\circ}$ during December $20^{\text {th }}-21^{\text {st }}$. The declination value is zero on March $22^{\text {nd }}$ and September $22^{\text {nd }}$ of the year, see Table 2.

Table 2

Monthly representative day and its corresponding declination $(\delta$ in degrees)

\begin{tabular}{lcccccc}
\hline Month & Jan. & Feb. & Mar. & Apr. & May & Jun. \\
\hline Day $(n)$ & 17 & 47 & 75 & 105 & 135 & 162 \\
Declination $(\delta)$ & -20.92 & -12.05 & -2.43 & 9.41 & 18.79 & 23.09 \\
\hline Month & July & Aug. & Sep. & Oct. & Nov. & Dec. \\
\hline Day $(n)$ & 198 & 228 & 258 & 288 & 318 & 344 \\
Declination $(\delta)$ & 21.18 & 13.46 & 2.22 & -9.60 & -18.91 & -23.05 \\
\hline
\end{tabular}

According to Cooper Cooper (1969), declination angle is calculated using the following relation:

$$
\delta=23.45 \sin \left[360 \frac{(284+n)}{365}\right]
$$

where $n$ is the day of the year.

Various researchers have proposed numerous models which are classified as isotropic including Liu and Jordan (1960), Tian (2001), Koronakis (1986) and Badescu (2002) and anisotropic Hay (1979), Reindl et al. (1990), Klucher (1979) models, Skartveit and Olseth (1986), and Steven and Unsworth (1980) to estimate solar radiation on inclined surfaces. However, according to Tang and Wu (2004), measured diffuse solar radiation data gives better estimates of the optimum tilt angle. In this study, measured data of global and diffuse solar radiation has been utilized to calculate the optimum tilt angles. Liu and Jordan (1960) (isotropic) model has been used to estimate total solar radiation on inclined flat surfaces facing south.

The angle of incidence for a surface oriented in any direction can be mathematically expressed by the following relation given by Duffie and Beckman (2006):

$\cos \theta=\sin \delta \sin \varphi \cos \beta-\sin \delta \cos \varphi \sin \beta \cos \gamma$

$+\cos \delta \cos \varphi \cos \beta \cos \omega+\cos \delta \sin \varphi \sin \beta \cos \gamma \cos \omega$

$+\cos \delta \sin \beta \sin \gamma \sin \omega$

For a surface in northern hemisphere facing south (i.e. $\gamma=0$ ) Eq. (16) can be simplified as:

$$
\cos \theta=\sin (\phi-\beta) \sin \delta+\cos (\phi-\beta) \cos \delta \cos \omega
$$

For a horizontal surface $(\beta=0)$, the angle of incidence $(\theta)$ becomes equal to zenith angle $\left(\theta_{z}\right)$. Substituting this value in Eq. (17), zenith angle can be written as:

$$
\cos \theta_{z}=\sin \varphi \sin \delta+\cos \varphi \cos \delta \cos \omega
$$

The total solar energy received on an inclined surface is the sum of beam and diffuse radiations directly incident on a surface and reflected radiations (reflected by the surroundings).

According to Liu and Jordan (1960), the beam conversion factor $\overline{R_{b}}$ is given as:

$$
\bar{R}_{b}=\frac{\cos (\phi-\beta) \cos \delta \sin \omega+(\pi / 180) \omega \sin (\phi-\beta) \sin \delta}{\cos \phi \cos \delta \sin \omega_{s}+(\pi / 180) \omega_{s} \sin \phi \sin \delta}
$$

Where $\omega$ is the sunrise (or sunset) hour angle for the inclined surface.

$$
\omega=\min \left\{\omega_{s}, \omega_{s}^{\prime}\right\}
$$

The hour angles at sunrise and sunset $\omega_{s}$ are very useful parameters. Since, numerically these two angles have the same value the sunrise angle is negative, and the sunset angle is positive. Both can be calculated from the following expression:

$$
\omega_{s}=\cos ^{-1}(-\tan \phi \tan \delta)
$$

If a surface is inclined from the horizontal, the Sun may rise over its edge after it has risen over the horizon. Therefore, the surface may shade itself for some days. The sunrise and sunset angles for an inclined surface $\left(\omega_{z}\right)$ 
facing the equator (i.e. facing south for the northern hemisphere) are given by:

$$
\omega_{s}^{\prime}=\cos ^{-1}(\tan (\phi-\beta) \tan \delta)
$$

\section{Results and Discussions}

Equations (1-22) are used to determine the monthly mean daily global solar radiation on the south-facing inclined surface for the location under study, Pristina. By changing the tilt angle from $0^{\circ}$ to $90^{\circ}$ in values of $0.1^{\circ}$, the optimal tilt angle is defined by the corresponding value of maximum solar radiation for a certain period.

Based on the methodology used in Section 3 and on the Liu and Jordan model (1960), estimations have been made to obtain the optimum monthly, seasonal, and yearly/annual tilt angles by corresponding to global solar radiation on an inclined surface - results are given in Table 3.

Table 3

The optimum monthly, seasonal, and annual tilt angles $B_{\text {opt }}\left({ }^{\circ}\right)$ for Pristina

\begin{tabular}{cccccccc}
\hline \multirow{2}{*}{ Station } & \multirow{2}{*}{ Period } & \multicolumn{6}{c}{ Month } \\
& & Jan. & Feb. & Mar. & Apr. & May & Jun. \\
\hline \multirow{2}{*}{$\begin{array}{c}\text { Pristina } \\
\phi=42^{\circ} 39^{\prime} \mathrm{N}\end{array}$} & Monthly & 64.8 & 56.5 & 43 & 25 & 9.2 & 0.3 \\
& Seasonal & 62.1 & 62.1 & 25.7 & 25.7 & 25.7 & 8.9 \\
& Annual & 34.7 & 34.7 & 34.7 & 34.7 & 34.7 & 34.7 \\
\hline \multirow{2}{*}{ Station } & \multirow{2}{*}{ Period } & \multicolumn{6}{c}{ Month } \\
& July & Aug. & Sep. & Oct. & Nov. & Dec. \\
\multirow{2}{*}{$\begin{array}{c}\text { Pristina } \\
\phi=42^{\circ} 39^{\prime} \mathrm{N} N\end{array}$} & Monthly & 4.8 & 19.2 & 37.3 & 54.3 & 63.8 & 66.4 \\
& Seasonal & 8.9 & 8.9 & 50.9 & 50.9 & 50.9 & 62.1 \\
& Annual & 34.7 & 34.7 & 34.7 & 34.7 & 34.7 & 34.7 \\
\hline
\end{tabular}

To continue with, the daily extraterrestrial radiation on a horizontal surface $\bar{H}_{0}$, clearness index $\bar{K}_{T}$, diffuse solar radiation on a horizontal plane $\bar{H}_{d}$, optimal tilt angle $B_{\text {opt }}$, monthly average daily global radiation in optimal tilt angle $\bar{H}_{T}$, and the comparison $\bar{H}$ with $\bar{H}_{T}$ in percentage, has also been estimated and are presented in Table 4,which shows the minimum and maximum value of $\bar{H}_{T}$, that correspond to December and July respectively.

Table 4

$\overline{\mathrm{H}}_{\mathrm{o}}\left(\mathrm{kWh} / \mathrm{m}^{2} /\right.$ day $), \overline{\mathrm{K}}_{\mathrm{T}}, \overline{\mathrm{H}}_{\mathrm{d}}\left(\mathrm{kWh} / \mathrm{m}^{2} /\right.$ day $), \beta_{\mathrm{opt}}\left({ }^{\circ}\right), \overline{\mathrm{H}}_{\mathrm{T}}\left(\mathrm{kWh} / \mathrm{m}^{2} /\right.$ day $)$ and comparison with $\overline{\mathrm{H}}$ in location Pristina city

\begin{tabular}{lcccccc}
\hline Month & $\overline{\mathrm{H}}_{\mathrm{o}}$ & $\overline{\mathrm{K}}_{\mathrm{T}}$ & $\overline{\mathrm{H}}_{\mathrm{d}}$ & $\beta_{\text {opt }}\left({ }^{o}\right)$ & $\overline{\mathrm{H}}_{\mathrm{T}}$ & $\overline{\mathrm{H}}_{\mathrm{o}} / \overline{\mathrm{H}}_{\mathrm{T}}(\%)$ \\
\hline January & 3.60 & 0.45 & 0.69 & 64.8 & 3.14 & 95.03 \\
February & 5.04 & 0.49 & 0.96 & 56.5 & 3.89 & 58.13 \\
March & 7.24 & 0.52 & 1.36 & 43 & 4.81 & 26.58 \\
April & 9.17 & 0.54 & 1.76 & 25 & 5.33 & 7.24 \\
May & 11.34 & 0.53 & 2.29 & 9.2 & 6.07 & 0.83 \\
June & 11.62 & 0.56 & 2.30 & 0.3 & 6.52 & 0.00 \\
July & 11.98 & 0.56 & 2.36 & 4.8 & 6.70 & 0.15 \\
August & 10.32 & 0.58 & 1.90 & 19.2 & 6.23 & 4.01 \\
September & 7.84 & 0.58 & 1.36 & 37.3 & 5.46 & 19.21 \\
October & 5.86 & 0.57 & 1.00 & 54.3 & 5.12 & 53.75 \\
November & 4.14 & 0.50 & 0.77 & 63.8 & 3.97 & 92.72 \\
December & 3.38 & 0.42 & 0.65 & 66.4 & 2.90 & 104.23 \\
Average & 7.63 & 0.53 & 1.45 & - & 5.01 & 21.34 \\
\% Gain & - & - & - & - & 21.35 & - \\
\hline & & & & & &
\end{tabular}
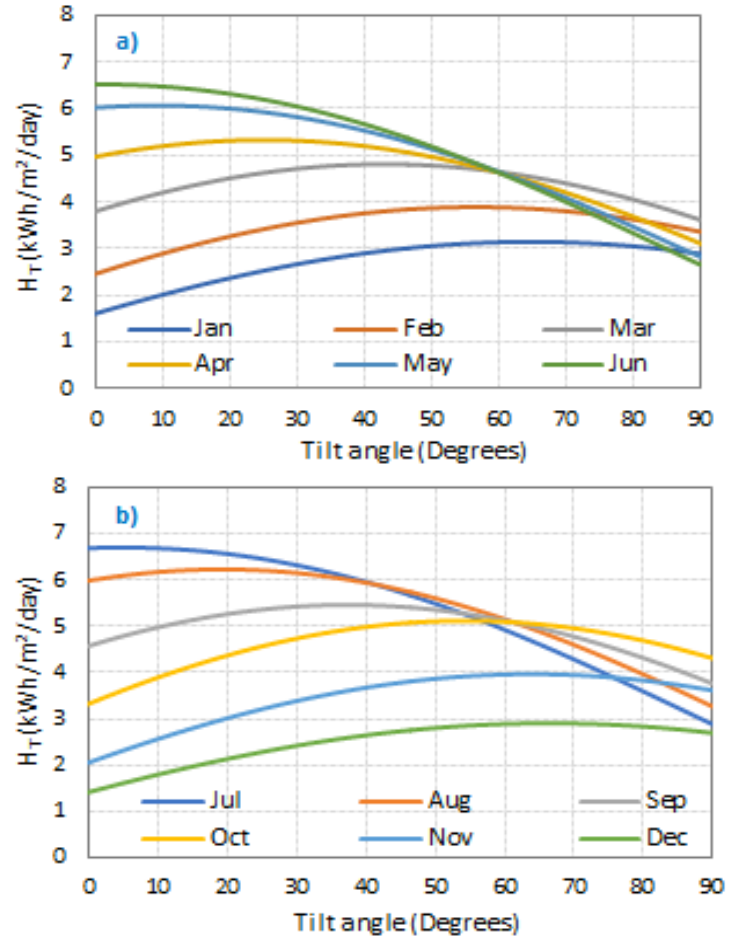

Fig. 4 Monthly mean solar radiation data for Pristina when the tilt angle variates from $0^{\circ}$ to $90^{\circ}$ : a) January-June and b) JulyDecember

For all the months and different tilt angles, monthly average total solar radiation was calculated using Eq. (1). The findings have been plotted and are shown in Fig. 4 for Pristina, where the tilt angle has been varied in the range of $0-90^{\circ}$ (in steps of $10^{\circ}$ ). Fig. 4.a) and 4.b) show the total solar radiation versus tilt angle from January to June and from July to December respectively. It is apparent from the Fig. 4 that the solar radiation is an intensive function of tilt angle. The calculated solar energy radiation incident on the flat surface is increased, with the increasing of horizontal position from $0^{\circ}$ to an angle of inclination, but a further increase of the tilt angle of the flat surface will result in the decreasing of solar radiation received.

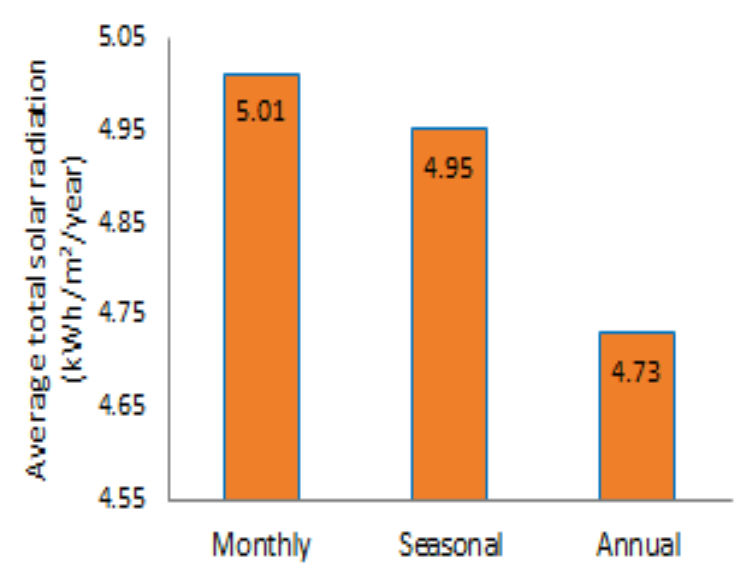

Fig. 5 Average maximum total solar optimum annual for Pristina 


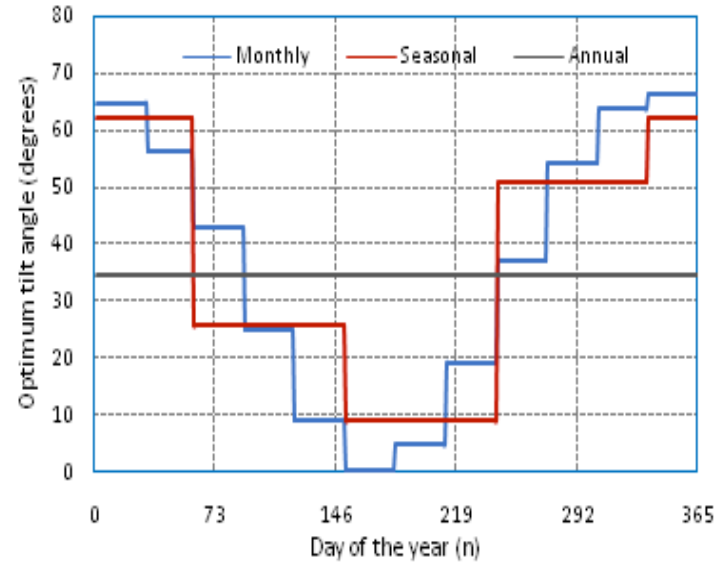

Fig. 6 Variations of monthly, seasonal \& annual optimum tilt angles for south-facing surface in Pristina

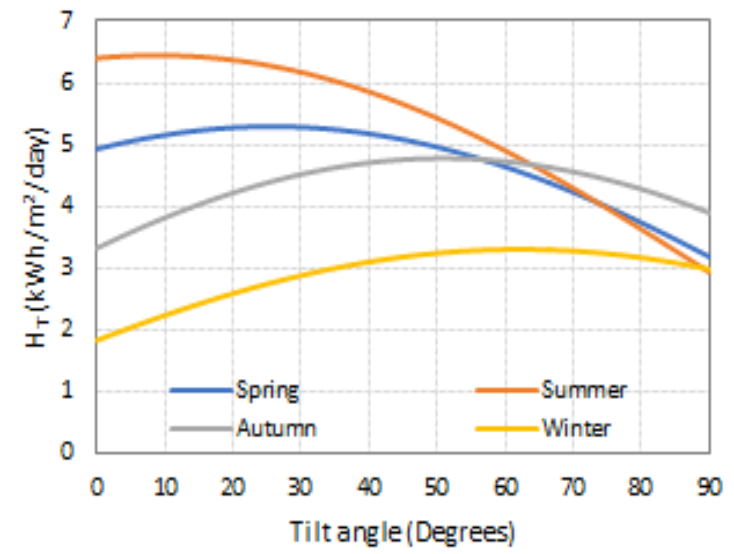

Fig. 7 Seasonal mean solar radiation in Pristina for: Spring, Summer, Autumn, Winter, when the tilt angle charges from 0o to $90^{\circ}$. (Considering the azimuth angle $=0$ o for maximum solar radiation).

The result also indicated that the optimum angle differs with the yearly months. The maximum solar radiation is achieved for every month with unique optimum tilt angle - which increases in winter months and decreases to the minimum value in summer \& autumn months, (see Fig. 5). Fig. 6 compares the average annual solar radiation on a tilted surface fixed at monthly, seasonal, and yearly optimum tilt angles for Pristina. As observed from the Fig. 6, the annual average total solar radiation estimated at monthly optimum tilt angle is found to be the highest, followed by average annual solar radiation estimated at seasonal and annual optimum tilt angles value.

The aforementioned optimal tilt angles are also plotted in Fig. 5.

Gains of solar radiation available on an inclined surface are defined as follows:

$\operatorname{Gains}(\%)=\left(\frac{\bar{H}_{T}\left(\beta=\beta_{\text {opt }, i}\right)}{\bar{H}_{T}(\beta=0)}-1\right) \times 100$

where $\mathrm{i}=$ monthly, seasonal and annual.

Therefore, four seasonal optimum tilt angles were obtained (corresponding to each season) $62.1^{\circ}$ in winter, $25.7^{\circ}$ in spring, $8.9^{\circ}$ in summer, and $50.9^{\circ}$ in autumn. Thus, winters have a higher value of optimum tilt angle, while summers observe a lower tilt angle value. Annual optimum tilt angle was calculated by using expressions from Section 3 and has resulted to be $34.7^{\circ}$ for Pristina.

Annual average total gains of solar radiation on an optimally tilted angle of a surface in comparison to a horizontal surface are $21.35 \%$ (monthly optimum tilt angle), $19.98 \%$ (seasonal optimum tilt angle) and $14.43 \%$ (annual optimum tilt angle).

Results for the diffuse radiation on a horizontal plane; the yearly (annual) and seasonal optimal tilt angles for each season; the monthly average daily global radiation for optimal tilt angle; and the comparison between $\mathrm{H}$ with $\mathrm{H}_{\mathrm{T}}$ in percentage are presented in Table 5 .

Table 5

$\overline{\mathrm{H}}_{\mathrm{d}}\left(\mathrm{kWh} / \mathrm{m}^{2} /\right.$ day $), B_{\text {opt }}\left({ }^{\circ}\right), \overline{\mathrm{H}}_{\mathrm{T}}\left(\mathrm{kWh} / \mathrm{m}^{2} /\right.$ day $)$ and the comparison with $\overline{\mathrm{H}}$ of Pristina for seasonal and annual tilt angles

\begin{tabular}{lcccccccc}
\hline \multicolumn{1}{c}{ Month } & \multirow{2}{*}{ Seasons } & $\overline{\mathrm{H}}_{\mathrm{d}}$ & $\begin{array}{c}\text { Seasonal } \\
\boldsymbol{\beta}_{\text {opt }}\end{array}$ & $\begin{array}{c}\text { Annual } \\
\boldsymbol{\beta}_{\text {opt }}\end{array}$ & $\begin{array}{c}\text { Seasonal } \\
\overline{\mathrm{H}}_{\mathrm{T}}\end{array}$ & $\begin{array}{c}\text { Annual } \\
\overline{\mathrm{H}}_{\mathrm{T}}\end{array}$ & $\begin{array}{c}\overline{\mathrm{H}}_{\mathrm{T}} / \overline{\mathrm{H}} \\
\text { Seasonal }\end{array}$ & $\begin{array}{c}\overline{\mathrm{H}}_{\mathrm{T}} / \overline{\mathrm{H}} \\
\text { Annual }\end{array}$ \\
\hline January & \multirow{2}{*}{ Winter } & 0.69 & 62.1 & 34.7 & 3.14 & 2.78 & 95.03 & 72.67 \\
February & & 0.96 & 62.1 & 34.7 & 3.88 & 3.66 & 57.72 & 48.78 \\
March & & 1.36 & 25.7 & 34.7 & 4.64 & 4.77 & 22.11 & 25.53 \\
April & \multirow{2}{*}{ Spring } & 1.76 & 25.7 & 34.7 & 5.33 & 5.27 & 7.24 & 6.04 \\
May & & 2.26 & 25.7 & 34.7 & 5.91 & 5.70 & -1.83 & -5.32 \\
June & & 2.29 & 8.9 & 34.7 & 6.48 & 5.88 & -0.61 & -9.82 \\
July & \multirow{2}{*}{ Summer } & 2.35 & 8.9 & 34.7 & 6.69 & 6.17 & 0.00 & -7.77 \\
August & & 1.90 & 8.9 & 34.7 & 6.16 & 6.07 & 2.84 & 1.34 \\
September & & 1.36 & 50.9 & 34.7 & 5.34 & 5.46 & 16.59 & 19.21 \\
October & \multirow{2}{*}{ Autumn } & 1.01 & 50.9 & 34.7 & 5.11 & 4.87 & 53.45 & 46.25 \\
November & & 0.76 & 50.9 & 34.7 & 3.88 & 3.54 & 88.35 & 71.84 \\
December & \multirow{2}{*}{ Winter } & 0.65 & 62.1 & 34.7 & 2.90 & 2.54 & 104.23 & 78.87 \\
Average & & 1.45 & - & - & 4.95 & 4.73 & 19.98 & 14.43 \\
\% Gain & & - & - & - & 19.98 & 14.43 & - & - \\
\hline
\end{tabular}


For all the months and different tilt angles, monthly average total solar radiations for the city of Pristina, were calculated using the procedure described in the previous section, based on the Liu \& Jordan model, estimates have been made to obtain optimum tilt angles and corresponding total solar radiation on inclined surfaces.

Figure 8 describes the variation of beam conversion factor with days of the year at various tilt angles for the city of Pristina. Also, Figure 9 shows the variation of diffuse and reflected conversion factors at different tilt angles.

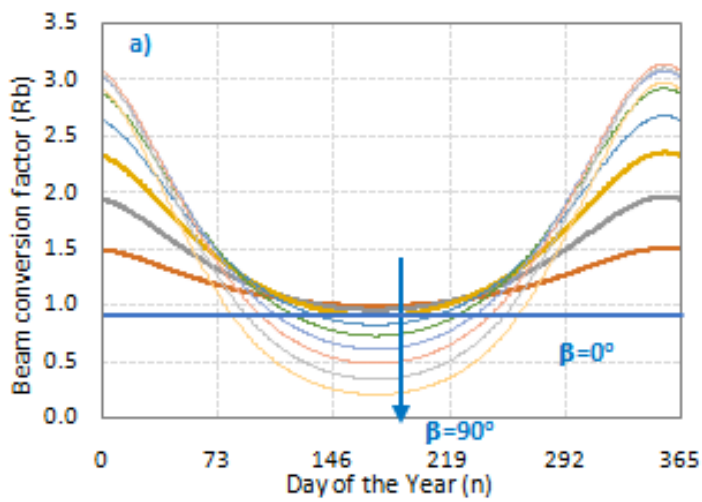

Fig. 8 Beam conversion factor at different tilt angles for Pristina

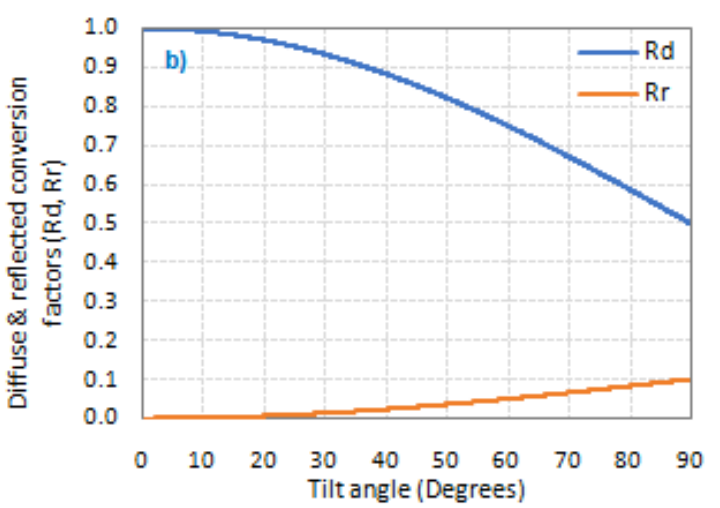

Fig. 9 Diffuse and reflected conversion factors for Pristina

\section{Conclusion}

By making adjustments in the surface inclination, energy falling on a surface can be significantly improved. Different months have different values for optimum tilt angles due to the change of the Sun's position. The following conclusions are drawn:

- Seasonal optimum tilt angles are $62.1^{\circ}$ (winter), $25.7^{\circ}$ (spring), $8.9^{\circ}$ (summer), and $50.9^{\circ}$ (autumn). Tilt angles are higher in winter rather than in summer.

- The Annual optimum tilt angle $\left(\beta_{\text {ogt }}\right)$ is $34.7^{\circ}$.

- Maximum and minimum values of total solar radiation at annual optimum tilt angle are 6.17 $\mathrm{kWh} / \mathrm{m}^{2} /$ day (July) and $2.54 \mathrm{kWh} / \mathrm{m}^{2} /$ day (December).

It is recommended that where possible the surface must be inclined at monthly or seasonal optimum tilt angles to reach the highest possible values of solar radiation. The annual optimum tilt angle can be used for surfaces with fixed inclination where the changing of tilt angle is not often possible.

By doing so, the system optimization is achieved to enable the highest absorption of solar radiation from an inclined surface.

\section{References}

Ahmad, A., Okoye, C.O., Atikol, U. (2016) The effect of latitude on the performance of different solar trackers in Europe and Africa. Applied Energy, 177, 896-906.

Ahmad, M.J, Tiwari, G.N. (2009) Optimization of tilt angle for solar collectors to receive maximum radiation. The Open Renewable Energy Journal, 2, 19-24.

Alatarawneh, I.S., Rawadieh, S.I., Tarawneh, M.S., Alrowwad, S.M., Rimawi, F. (2016) Optimal tilt angle trajectory for maximizing solar energy potential in Ma'anareain in Jordan. Journal of Renewable Sustainable Energy, 8.

Alboteanu, I., Bulucea, C., Degeratu, S. (2015) Estimating Solar Irradiation Absorbed by Photovoltaic Panels with Low Concentration Located in Craiova, Romania. Sustainability, 7(3), 2644-2661.

Badescu, V. (2002) A new kind of cloudy sky model to compute instantaneous values of diffuse and global solar irradiance. Theoretical and Applied Climatology, 72(1-2), 127-136.

Bakirci , K. (2012) General models for optimum tilt angles of solar panels: Turkey case study. Renewable and Sustainable Energy Reviews, 16(8), 6149-6159.

Benghanem, M. (2011) Optimization of tilt angle for solar panel: Case study for Madinah, Saudi Arabia. Applied Energy, 88(4), 1427-1433.

Calabr, E. (2013) An algorithm to determine the optimum tilt angle of a solar panel from global horizontal solar radiation. Journal of Renewable Energy, 12.

Cooper, P.I. (1969) The absorption of radiation in solar stills. Sol. Energy, 12(3), 333-346.

Duffie, J., Beckman, W. (2006) Solar Engineering of Thermal Processes, Part I, Fundamentals 1, 4th edn. John Wiley, New York.

Eke, A.B. (2011) Prediction of optimum angle of inclination for flat plate solar collectors in Zaria, Nigeria. Agricultural Engineering International: CIGR Journal, 13(4).

Eldin, S.A.S., Abd-Elhady, M.S., Kandil, H.A. (2016) Feasibility of solar tracking systems for PV panels in hot and cold regions. Renewable Energy, 85, 228-233.

Elminir, H.K., Ghitas, A.E., El-Hussainy, F., Hamid, R., Beheary, M.M., Abdel-Moneim, K.M. (2006) Optimum solar flat-plate collector slope: Case study for Helwan, Egypt. Energy Conversion Management, 47(5), 624-637.

Ertekin , C., Evrendilek, F., Kulcu, R. (2008) Modeling SpatioTemporal Dynamics of Optimum Tilt Angles for Solar Collectors in Turkey. Sensors, 8, 2913.

Handoyo, E.A., Ichsani, D., Prabowo. (2013) The Optimal Tilt Angle of a Solar Collector. Energy Procedia, 32, 166-175.

Hartner, M., Ortner, A., Hiesl, A., Haas, R. (2015) East to west The optimal tilt angle and orientation of photovoltaic panels from an electricity system perspective. Applied Energy, 160, 94-107.

Hay, J.E. (1979) Calculation of monthly mean solar radiation for horizontal and inclined surfaces. Solar Energy, 23(4), 301307.

Jafari, S., Javaran, E. J. (2012) An Optimum Slope Angle for Solar Collector Systems in Kerman Using a New Model for Diffuse Solar Radiation. Energy Sources, Part A: Recovery, Utilization, and Environmental Effects, 34(9), 799-809. 
Jafarkazemi, F., Saadabadi, S.A. (2013) Optimum tilt angle and orientation of solar surfaces in Abu Dhabi, UAE. Renewable Energy, 56, 44-49.

Jafarkazemi, F., Saadabadi, S.A., Pasdarshahri, H. (2012) The optimum tilt angle for flat plate solar collectors in Iran. Journal of Renewable Sustainable Energy, 4, 215-223.

Jakhrani, A.Q., Samo, S.R., Rigit, A.R.H., Kamboh, S.A. (2013) Selection of models for calculation of incident solar radiation on tilted surface. World Applied Sciences Journal, 22(9), 1334-1343.

Khahro, S.F., Tabbassum, K., Talpur, S., Alvi, M.B., Liao, X., Dong, L. (2015) Evaluation of solar energy resources by establishing empirical models for diffuse solar radiation on tilted surface and analysis for optimum tilt angle for a prospective location in southern region of Sindh, Pakistan. International Journal of Electrical Power \& Energy Systems, 64, 1073-1080.

Klein, S.A. (1977) Calculation of monthly average insolation on tilted surfaces. Solar Energy, 19(4), 325-329.

Klucher, T.M. (1979) Evaluation of models to predict insolation on tilted surfaces. Solar Energy, 23(2), 111-114.

Kondratev, I.K.A. (1969) Diffuse Radiation of the Atmosphere. International Geophysics, 12, 363-410.

Koronakis, P.S. (1986) On the choice of the angle of tilt for south facing solar collectors in the Athens basin area. Solar Energy, 36(3), 217-225.

Krishna, S.M., Madhu, M.N., Mohan, V., Suresh, M.P.R., Singh, J.G. (2015) A generalized approach for enhaced solar energy harvesting using stochastic estimation of optimum tilt angles: a case study of Bangkok City. Green, 5, 1-6.

Li, D.H.W., Lam, T.N.T. (2007) Determining the optimum tilt angle and orientation for solar energy collection based on measured solar radiance data. International Journal of Photoenergy, ID 85402, 9,

Liu, B., Jordan, R. (1962) Daily insolation on surfaces tilted towards the equator. ASHREA, 67, 526-541. http://www.worldcat.org/title/daily-insolation-on-surfacestilted-towards-equator/.

Liu, B.Y.H., Jordan, R.C. (1960) The interrelationship and characteristic distribution of direct, diffuse and total solar radiation. Solar Energy, 4 (3), 1-19.

Mehleri, E.D., Zervas, P.L., Sarimveis, H., Palyvos, J.A., Markatos, N.C. (2010) Determination of the optimal tilt angle and orientation for solar photovoltaic arrays. Renewable Energy, 35(11), 2468-2475.

Moghadam, H., Tabrizi, F.F., Sharak, A.Z. (2011) Optimization of solar flat collector inclination. Desalination, 265(1-3), $107-111$

Muneer, T. (2004) Solar Radiation and Day Light Models, 2nd edn. Elsevier, Oxford.

Naumann, E., Pireci, M. (2012) Identification of potential or application of solar energy technology in the municipality of Dragash. http://www.ks.undp.org/content/dam/kosovo/docs/dragash/ .../02042012-Eng.pdf?doenload.

Okoye, C.O., Taylan, O., Baker, D.K. (2016) Solar energy potentials in strategically located cities in Nigeria: Review, resource assessment and PV system design. Renewable and Sustainable Energy Reviews, 55, 550-566.

Paul W. S. Jr, William S. C., Taiping Z. (2016) Surface meteorology and Solar Energy (SSE), https://eosweb.larc.nasa.gov/sse/documents/SSE6Methodol ogy.pdf Accessed on 11 January 2017.

Reindl, D.T., Beckman, W.A., Duffie, J.A. (1990) Evaluation of hourly tilted surface radiation models. Solar Energy, 45(1), 9-17.

Robinson, D., Stone, A. (2004) Solar radiation modeling in the urban context. Solar Energy, 77(3), 295-309.

Shariah, A., Al-Akhras, M.-A., Al-Omari, I.A. (2002) Optimizing the tilt angle of solar collectors. Renewable Energy, 26(4), 587-598.
Sinha, S., Chandel, S.S. (2016) Analysis of fixed tilt and sun tracking photovoltaic-micro wind based hybrid power systems. Energy Conversion Management, 115, 265-275.

Siraki, A.G., Pillay, P. (2012) Study of optimum tilt angles for solar panels in different latitudes for urban applications. Solar Energy, 86(6), 1920-1928.

Skartveit, A., Olseth, A.J. (1986) Modelling slope irradiance at high latitudes. Solar Energy, 36(4), 333-344.

Skeiker, K. (2009) Optimum tilt angle and orientation for solar collectors in Syria. Energy Conversion and Management, 50(9), 2439-2448.

Soulayman, S and Sabbagh, W (2015) Optimum Tilt Angle at Tropical Region. Int. Journal of Renewable Energy Development, 4(1), 48-54.

Stanciu, D., Stanciu, C., Paraschiv, I. (2016) Mathematical links between optimum solar collector tilts in isotropic sky for intercepting maximum solar irradiance. Journal of Atmospheric and Solar-Terrestrial Physics, 137, 58-65.

Steven, M.D., Unsworth, M.H. (1980) The angular distribution and interception of diffuse solar radiation below overcast skies. Quarterly Journal of the Royal Meteorological Society, 106, 57-61.

Tamimi, A., Sowayan, A. (2012) Optimum Tilt Angles of Flatplate Solar Collectors at Riyadh, Kingdom of Saudi Arabia. Energy Sources, Part A: Recovery, Utilization, and Environmental Effects, 34(13), 1213-1221.

Tang, R., Wu, T. (2004) Optimal tilt-angles for solar collectors used in China. Applied Energy, 79(3), 239-248.

Tian, Y.Q., Davies-Colley, R.J., Gong, P., Thorold, B.W. (2001) Estimating solar radiation on slopes of arbitrary aspect. Agricultural and Forest Meteorology, 109(1), 67-74.

Vieira, R.G., Guerra, F.K.O.M.V., Vale, M.R.B.G., Araújo, M.M. (2016) Comparative performance analysis between static solar panels and single-axis tracking system on a hot climate region near to the equator. Renewable and Sustainable Energy Reviews, 64, 672-681.

World Bank Group (2017) Solargis \& Energy Sector Management Assistance Program. Poster Maps for Kosovo, http://globalsolaratlas.info/downloads/kosovo Accessed on 21 February 2017.

Widén, J. (2009) Distributed photovoltaic in the Swedish energy system. Licentiate thesis, Uppsala University Sweden.

Yakup, M.A. bin H.M., Malik, A.Q. (2001) Optimum tilt angle and orientation for solar collector in Brunei Darussalam. Renewable Energy, 24(2), 223-234. 